Educational Studies, Vol. 27, No. 3, 2001

\title{
Individual Learning Style and the Learning Style Inventory
}

\section{BO HEFFLER}

Departent of Psychology, Stockholm University, S-106 91 Stockholm, Sweden

SUMMARY According to experience learning theory (ELT) learning is a process. ELT conceives of learning as a four-stage cycle including four learning modes: concrete experience, reflective observation, abstract conceptualization and active experimentation. The learning style inventory (LSI) invented from ELT provides a framework for examining one's approach to learning situations. The aim of the present study was to collect data with the LSI and present: (a) the test-retest reliability coefficients for the different learning modes; (b) the correlation between different learning modes and age; (c) gender differences in the learning modes; and (d) homogeneous groups of students with different learning styles. The results showed highly significant reliability coefficients, non-significant correlations between learning modes and age, gender differences in some learning modes, and a cluster analysis found homogenous groups with different learning styles.

\section{Introduction}

In my work as a lecturer, I have noticed inter-individual differences in students' motivation and activities during the different elements of my courses in developmental psychology. I have been reflecting over possible relationships and correlations between my way of planning and executing the course, on the one hand, and students' motivation and learning results on the other. The interaction with students, their reactions to the offered activities and exams, and the learning outcome of the course, have made me aware of the necessity of accepting different inter-individual approaches to learning, and the possibility of different learning styles. I found that if I could offer educational alternatives and individualize the learning experience, the end result improved and the course evaluation increased.

However, learning style researchers define differences differently (Dunn et al., 1981). According to experience learning theory (ELT) (Kolb, 1984) learning is a process; ELT conceives of learning as a four-stage cycle including concrete experience ('feeling'), reflective observation ('watching'), abstract conceptualization ('thinking'), and active experimentation ('doing'). All four stages should be activated in every optimal learning process, the individual learner alternates between a concrete experience, reflective observation, then thinking and analyzing, and finally the testing activity. But learners generally report 
themselves as preferring certain ways of learning. They report themselves as being one of four types, that emanate from different combinations of the four stages above: divergers, assimilators, convergers or accommodators. A forerunner phenomenon is also found in developmental psychology. Children and students could often be categorized as either hear-learners, see-learners, or do-learners (Felder \& Silverman, 1988; Barbe \& Milone, 1981). So it seems reasonably safe to presume that we do have different personal learning styles. The question arises as to whether this personal learning style differs with age, or if it could be seen as a rather stable personal characteristic?

The individual learning style has both strengths and weaknesses depending on what is to be learnt and how. From a teacher's point of view, you can take this into consideration and plan for different learning activities. But as there is an interaction between the teaching and learning processes, the individual learner has a responsibility of his own. In the long run, people learn more effectively as they develop learning skills in their area of weakness (Stice, 1987).

David Kolb (1984) has invented a learning-style inventory (LSI) to help people assess their ability to learn from experience. Based on the theories of Dewey, Lewin and Piaget, the inventory provides a framework for examining one's own approach to learning situations, and, depending on the learning material and situation, one's own strengths and weaknesses. It is advantageous to know your own learning style, when approaching a new learning situation to optimize the outcome; and for teachers to know the learning styles of the student group in order to organize the curriculum with reference to the learning process as a whole. The first step to making this inventory a tool for further studies on this learning process is to measure its reliability.

The purpose of the investigation was to collect data with the LSI and present:

(1) test-retest reliability coefficients for the different learning modes;

(2) the correlation between different learning modes and age;

(3) gender differences in the learning modes; and

(4) homogenous groups of students with different learning styles, if there are any.

\section{Method}

\section{Respondents}

The respondents were students taking part in the first semester at the general psychology course at the Department of Psychology, Stockholm University, in February 1999. Data were collected twice with 85 respondents (64 females and 21 males) the first time, and 70 (56 females and 14 males) the second time. The age range was from 19 to 37 years of age. Those who took part both times were 61 students (49 females and 12 males). The test-retest reliability is built on those taking part on both occaisons. 


\section{Inventory}

The inventory is a nine-item self-description questionnaire. The selfdescriptions concern four different approaches to learning, i.e. learning style: concrete experience (CE) ('feeling'), reflective observation (RO) ('watching'), abstract conceptualization (AC) ('thinking'), and active experimentation (AE) ('doing'). The respondent is asked to rank-order four words in a way that best described his or her learning style. In each item, one word corresponds to one of the four learning modes. Here is an example of the first two items:

1. discriminating-tentative-involved -practical

2. receptive -relevant-analytical-impartial

$\mathrm{He} / \mathrm{she}$ is asked to rank order the words in each item by assigning a 4 to the word that best characterizes his or her learning style, a 3 to the word which next best characterizes the respondents learning style, a 2 to the next most characteristic word, and a 1 to the word which is least characteristic for him or her as a learner. The instruction says that 'You might find it hard to choose among the words that best characterize your learning style. Nevertheless, keep in mind that there are no right or wrong answers, all choices are equally acceptable. The aim of the inventory is to describe how you learn, not to evaluate your learning ability.'

In accordance with a system, six of the nine-item rank order numbers are added for each of the four columns, yielding four sums of rank orders. The higher the sum of rank orders for a given column, the more it indicates a preponderant or typical learning style for the individual. The rank order procedure makes it impossible to get a very high sum in all four learning modes.

Instead of the sum from each of the four different learning modes, it is possible to obtain the difference between AC vs. CE, and RO vs. AE. The first difference represents the abstract vs. concrete dimension of knowledge, the second one the intention vs. extension dimension of knowledge (Kolb, 1984). With these two difference measures, each individual could be represented as a point in a coordinate system, this point showing the preferential learning mode for that individual. Each quadrant in this coordinate system can be described as a typical learning style: the $\mathrm{CE}$ and RO quadrant is called 'diverger' (e.g. creative, good at generating alternatives, understanding people), the RO and AC quadrant 'assimilator' (e.g. creating theoretical models, inductive reasoning, defining problems), the AC and AE quadrant 'converger' (e.g. practical application of ideas, making decisions, selecting among alternatives), and finally the $\mathrm{AE}$ and $\mathrm{CE}$ quadrant 'accomodator' (e.g. gets things done, takes risks, tends to act on feelings).

\section{Procedure}

The original (test) version of the inventory was presented the first time. It took approximately 15 minutes to fill in the questionnaire. The second (retest) 
version was presented two weeks later in a similar situation to the first one. To lessen the memory effects from the test version to the retest version, the order of both the columns and the nine-item rows were changed in the retest version.

\section{Calculations}

The product-moment correlation coefficients were used as the test-retest measure for each learning mode, and also for learning mode vs. age. The sex differences were calculated using a $t$-test. To find the different learning style groups, a cluster analysis was used: Ward's hierarchical cluster analysis (Ward, 1963).

\section{Results}

\section{Test-rest Reliability}

The test-retest correlation coefficients for the different learning modes as a measure of the reliability of the instrument are presented in Table I. All the reliability coefficients are highly significant. The highest reliability was obtained for the RO learning mode $(r=0.81)$, and the lowest for the AC learning mode $(r=0.63)$. The correlations show in general that the active-reflective dimension ( $\mathrm{AE}$ and $\mathrm{RO}$ ) is more reliable or more stable than the abstract-concrete dimension, even though the latter is highly significant in the test-retest correlation. Overall, the result indicates that the learning style of the individual could be reliably measured with this inventory.

TABLE I. Test-retest correlation coefficients for each learning mode, and for both test-retest situation vs. age: concrete experience (CE), reflective observation (RO), abstract conceptualization (AC) and active experimentation (AE). Also shown are the corresponding correlation coefficients for the learning mode differences (the dimension abstract-concrete AC-CE, and the dimension extension-intension, $\mathrm{AE}-\mathrm{RO}$, respectively). (test-retest $n=61$; test version vs. age $n=85$; retest version vs. age $n=69$ ).

\begin{tabular}{lcrr}
\hline Learning mode & $\begin{array}{c}\text { Test vs. } \\
\text { retest }\end{array}$ & \multicolumn{2}{c}{$\begin{array}{c}\text { Learning mode vs. Age } \\
\text { Test sit. }\end{array}$} \\
\hline Retest sit. \\
RO & $0.65^{\star \star \star}$ & 0.17 & 0.05 \\
AC & $0.81^{\star \star \star}$ & -0.13 & -0.13 \\
AE & $0.63^{\star \star}$ & 0.03 & 0.06 \\
AC-CE & $0.74^{\star \star \star}$ & -0.08 & 0.06 \\
AE-RO & $0.71^{\star \star \star}$ & -0.08 & 0.00 \\
\hline
\end{tabular}

${ }^{\star} p=0.05 ;{ }^{\star \star} p=0.01 ;{ }^{\star \star \star} p=0.0001$. 
Learning Mode vs. Age

The correlations between each learning mode and age are also shown in Table I. The coefficients are all very close to zero and non-significant. This means that those different learning modes are not related to the age of the respondents, at least for the age range of the participating respondents (19-37 years of age).

\section{Sex Differences}

The differences in the test (original) version between males and females in the learning approach/mode are shown in Table II.

Table II shows that there are significant sex differences in the concrete experience learning mode, with females scoring higher. A higher score in this learning mode means, according to the construction of this inventory, an experience-based approach to learning, feeling-based judgements, peopleoriented, role-play simulation, and feeling comfortable with ambiguity. The close to significant sex difference in abstract conceptualization, with males scoring higher, contributes to the overall significant sex difference in the $\mathrm{AC}-\mathrm{CE}$, i.e. abstract vs. concrete dimension. A high score in AC indicates an analytic approach to learning, a logical and rational orientation towards things and symbols, and respect for authority and structure.

The mean for each group and dimension is also depicted in Fig. 1 as a learning style profile. The significant sex differences obtained in Table II for both the learning mode 'concrete experience' (CE) and for the 'abstract vs. concrete' dimension (AC-CE) can be seen as part of a learning style profile difference between males and females. The groups are closer to each other in

TABLE II. Test of sex difference for each learning mode, i.e. CE, RO, AC and AE. Also shown are the corresponding sex differences concerning learning mode differences (the dimension abstract-concrete, $\mathrm{AC}-\mathrm{CE}$, and the dimension extension-intension, AE-RO, respectively) (male $n=21$; female $n=63$ )

\begin{tabular}{lcrrrrrr}
\hline Variable & \multicolumn{2}{c}{ Male } & \multicolumn{2}{c}{ Female } & Diff. & $t$-value & $p$-value \\
\hline CE & M & 14.8 & M & 16.76 & -1.95 & -2.66 & 0.009 \\
& SD & 2.77 & SD & 2.96 & & & \\
RO & $\mathrm{M}$ & 14.76 & $\mathrm{M}$ & 14.42 & 0.34 & 0.36 & 0.718 \\
& $\mathrm{SD}$ & 3.32 & $\mathrm{SD}$ & 3.86 & & & \\
AC & $\mathrm{M}$ & 17.43 & $\mathrm{M}$ & 16.09 & 1.33 & 1.79 & 0.078 \\
& $\mathrm{SD}$ & 3.30 & $\mathrm{SD}$ & 2.86 & & & \\
AE & $\mathrm{M}$ & 13.19 & $\mathrm{M}$ & 14.28 & -1.09 & -1.20 & 0.232 \\
& $\mathrm{SD}$ & 3.14 & $\mathrm{SD}$ & 3.74 & & & \\
AC-CE & $\mathrm{M}$ & 2.62 & $\mathrm{M}$ & -0.68 & 3.30 & 2.51 & 0.014 \\
& $\mathrm{SD}$ & 5.55 & $\mathrm{SD}$ & 5.12 & & & \\
AE-RO & $\mathrm{M}$ & -1.57 & $\mathrm{M}$ & -0.14 & -1.43 & -0.85 & 0.398 \\
& $\mathrm{SD}$ & 6.01 & $\mathrm{SD}$ & 6.90 & & & \\
\hline
\end{tabular}




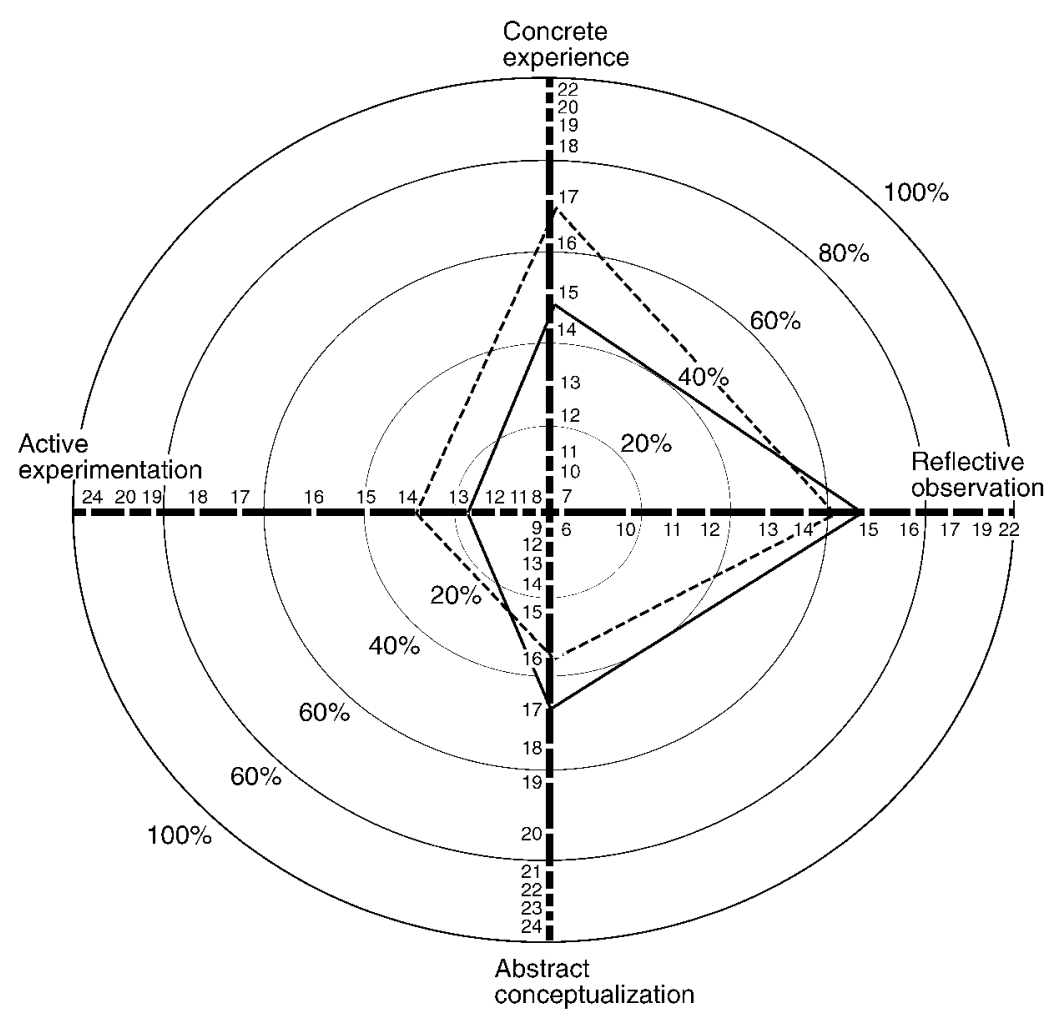

FIG. 1. The Learning Style Profile for each sex in the test (original) situation $(n=63$ for females, $n=21$ for males). Dotted line $=$ females, continous line $=$ males.

the active-reflective dimension, and more different in the abstract-concrete dimension.

\section{Cluster Analysis}

Ward's hierarchical cluster analysis, including all subjects in situation one, was used to find out if there were different typical profiles according to the four dimensions. A five-cluster solution was chosen which explained $57 \%$ of the variance. The different profiles are presented in Fig. 2.

According to the Learning Style Model, cluster A can be labeled assimilator with its emphasis on the RO dimension and the AC dimension, i.e. less focused on people, more focused on abstract concepts and ideas. Respondents in cluster $\mathrm{B}$ emphasize the $\mathrm{AE}$ dimension with the ability to learn from active experience and practical applications. The third cluster $\mathrm{C}$ is very high on CE preferring the concrete, tangible, felt qualities of the world, and low on abstract conceptualization, AC. The fourth cluster D represents a more balanced profile with all four dimensions represented. The last cluster $\mathrm{E}$ shows a profile quite typical for a 

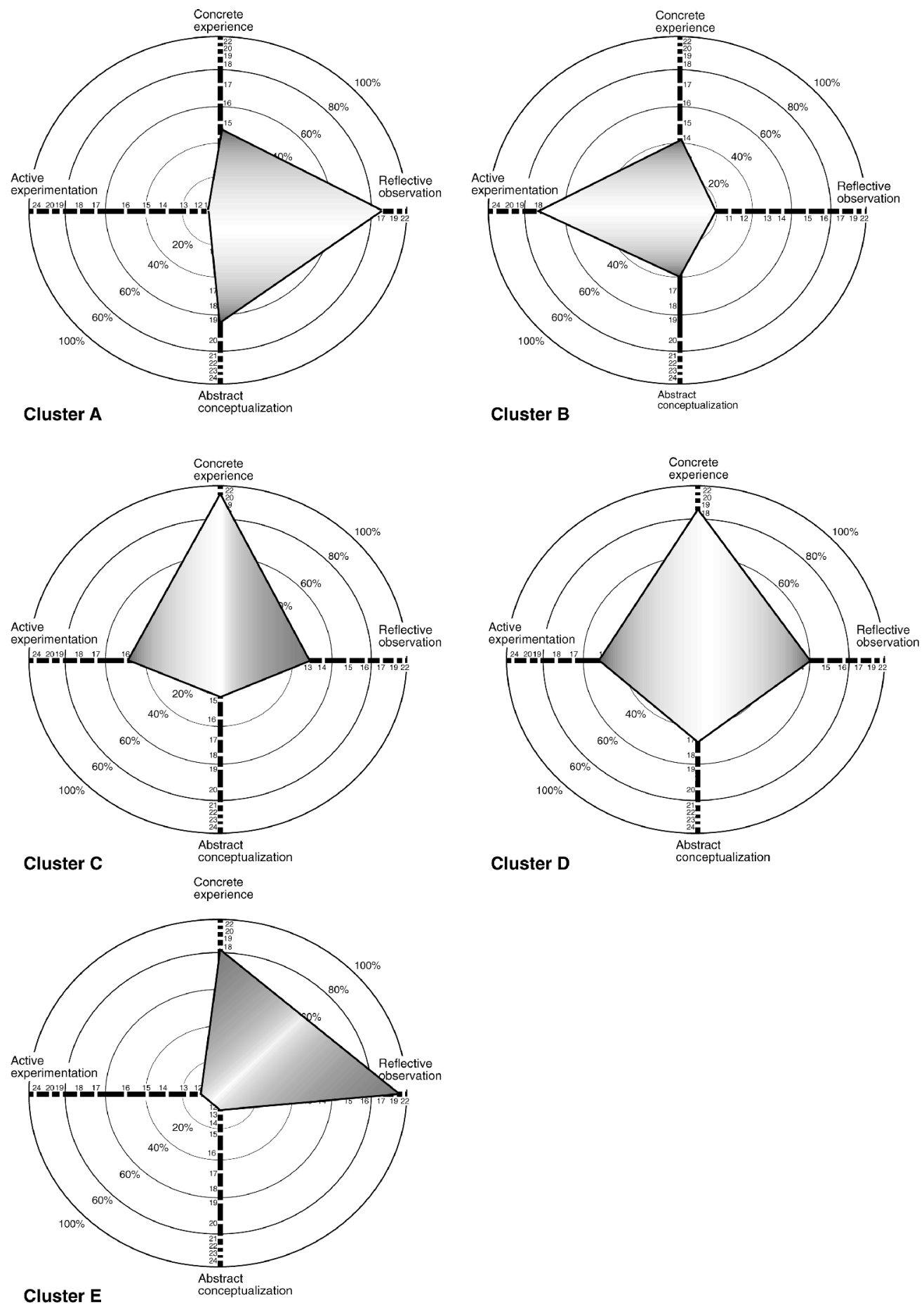

FIG. 2. The five-cluster solution in Ward's hierarchical cluster analysis. Each cluster representing a special learning style. Cluster $\mathrm{A}=$ assimilator, cluster $\mathrm{B}=$ accommodator/converger, cluster $\mathrm{C}=$ accommodator/diverger, cluster $\mathrm{D}=$ more balanced, and cluster $\mathrm{E}=$ diverger. See text for explanation. 
diverger; the diverging style's dominant learning abilities are a combination of concrete experience $\mathrm{CE}$ and reflective observation RO.

\section{Discussion}

The learning style of the individual seems to be reliably measured by the LSI with reference to the empirical test-retest study presented here. The correlations show that the active-reflective dimension ( $\mathrm{AE}$ and $\mathrm{RO}$ ) is more reliable or more stable than the abstract-concrete dimension, even though the latter is highly significant in test-retest correlation. Other studies have shown comparable reliability coefficients for this inventory (Kolb, 1984; Martensson, 1988). Since the presented data collection was performed, an article by Kolb et al. (1999) has referred to a more recent version of the LSI that has further improved the test-retest reliability. This means that by using the revised inventory, the psychometric properties of the Swedish version might improve even further.

The ELT emphasizes the central role that experience plays in the learning process, and has its intellectual origins in the works of Dewey, Lewin and Piaget. According to Piaget (Flavell, 1963) there is a particular tendency to become more analytic and reflective with age. However, the individual rankings within the population tested remain highly stable from early childhood to adulthood (Kolb, 1984). The age range of the sample tested here (19-37) is well situated in the formal operational period in Piaget's terms. Their cognitive and learning style has to a greater extent been an integral part of their personality. This is confirmed in the present study where in both situations the correlations between dimension(s) and age are close to zero. The learning style is not in a systematic way correlated to age.

A significant gender difference was obtained in the concrete experience learning mode with females scoring higher, i.e. a more experience-based approach to learning, feeling-based judgements, people-oriented, concrete roleplay simulation learning, and feeling comfortable with ambiguity. Also in combination with the opposite dimension, i.e. abstract vs. concrete learning mode, the AC-CE yielded an overall gender difference. A high score in AC indicates an analytic approach to learning, a logical and rational orientation towards things and symbols, and respect for authority and structure. At face value, the significant gender differences ( $\mathrm{CE}$ and $\mathrm{AC}-\mathrm{CE}$ ) and non-significant ( $\mathrm{AE}$ and $\mathrm{RO}$ ) seem reasonable and are in accordance with gender patterns and roles. It would be of interest to study LSI gender differences in certain learning situations, e.g. where the abstract and/or concrete learning modes were more focused and stressed. The LSI asks for a general approach to learning situations, i.e. what would it be like if you define the learning situation in more narrow terms in any of the four extremes; feeling, watching, thinking and doing? Would the gender difference still hold?

By choosing a five-cluster solution, the Ward's hierarchical cluster analysis showed some interesting patterns. According to the Learning Style Model, one cluster can be labeled assimilator with its emphasis on the RO dimension and 
the AC dimension, i.e. less focused on people, more focused on abstract concepts and ideas. With reference to a recent chapter by Kolb et al. (1999), these assimilators emphasize the logical soundness, rather than the practical value, of a theory. This learning style is important for effectiveness in information and science careers. The assimilators prefer formal learning situations readings, lectures, exploring analytical models, and want to have time to think things through. Respondents in the second cluster represent the opposite; they emphasize the $\mathrm{AE}$ dimension with the ability to learn from active experience and practical application. In the book mentioned above, Kolb would attribute this cluster to Westerners who specialize in $\mathrm{AE}$ and integrate the learning modes of $\mathrm{CE}$ and $\mathrm{AC}$. The third cluster is very high on CE, preferring the concrete, tangible, felt qualities of the world, as well as being low on abstract conceptualization, AC. It is similar to the second one, but these Northerners specialize in concrete experience, and integrate the dialectics of RO and AE. The fourth cluster represents a more balanced profile, with all four dimensions represented to a greater extent than the others. It is still high on $\mathrm{CE}$, integrating the $\mathrm{RO}$ and $\mathrm{AE}$ dimension, but compared with the above, Northerners are higher on the AC learning mode. The last cluster shows a profile quite typical for a diverger; the diverging style's dominant learning abilities are a combination of $\mathrm{CE}$ and $\mathrm{RO}$, viewing concrete situations from many different points, being best in situations that call for the generation of ideas. The ELT research shows that divergers are interested in people, tend to be imaginative and emotional, have broad cultural interests, and specialize in arts and in service organizations. With respect to formal learning situations, they prefer group work, are open minded when listening, and prefer receiving personalized feeback.

In the present study, a five-cluster solution was chosen according to two criteria; the clusters were psychologically interpretable from the theory, and a fair amount of the variance was explained. The cluster analysis could be seen as a pilot search for clusters or patterns in the data. The next step would be to compare comparisons between clusters and other data of interest, e.g. course/ study evaluations, study/examination results, choice of study programme, job assessment, attitudes and patient interaction etc. Recently some interesting results have been presented at Karolinska Institute, Stockholm, Sweden, concerning medical students learning style preferences and correlations with their attitudes and compliance (Martensson et al., 1999). Results of interest related to this study indicate that 'doers' (i.e. convergers and accommodators) compared with 'observers' (i.e. divergers and assimilators) do not see the physician's work as being imbedded with ethical considerations to the same extent; 'experiencing' (i.e. accommodators and divergers) students use Medline much less often compared with 'analytical' (i.e. convergers and assimilators) students. Furthermore, the groups of medical students choosing different specialties such as internal medicine, surgery and pediatrics, all showed different profiles from the four dimensions. Some data have recently been collected within the psychologist programme at Stockholm University, Sweden, which might shed some light on the issues concerning learning style and professional approach. 


\section{Acknowledgements}

This study was assisted by a grant from the Faculty of Social Sciences, Stockholm University. A special thank to Ola Andersson, BA, for the cluster analysis work.

\section{REFERENCES}

BARbe, W.B. \& MILONE M.N. JR (1981) What we know about modality strengths, Educational Leadership. Fournal of the Association for Supervision and Curriculum Development, 38, pp. 378380.

Dunn, R. \& De Bello, T. with Brennan, P., Krimsky, J. \& Murrain, P. (1981) Learning style researchers define differences differently, Educational leadership, fournal of the association for supervision and curriculum development, 38, pp. 372-375.

FELDER, R.M. \& SILVERMAN, L.K. (1988) Learning and teaching styles in engineering education, Engineering Education, April 1988, pp. 674-680.

Flavell, J.H. (1963) The Developmental Psychology of fean Piaget (New York, van Nostrand).

Kolb, D.A. (1984) Experiential Learning: experince as the source of learning and development (Englewood Cliffs, NJ: Prentice Hall).

Kolb, D.A., Boyatzis, R.E. \& MAINemelis, C. (1999) Experiential learning theory: previous research and new directions, in R.J. STERnberg \& L.F. ZHANG (Eds) Perspectives on Cognitive, Learning and Thinking Styles (Hillsdale, NJ: Lawrence Erlbaum).

MARTENSSON, D. (1988) Studieteknik och inlärningsstil hos KI-studerande, Karolinska Institutet: Institutionen för medicinsk undervisning. Rapport $n r 47$.

Martensson, D., BruchFeld, D. \& Bagedahl-STrindlund, M. (1999). Medical Students' learning style preferences: correlations with their attitudes and compliance, Association for Medical Education in Europe (AMEE) Annual Meeting in Linköping 29 August-1 September, Abstracts.

STICE, J.E. (1987) Using Kolb's learning cycle to improve student learning, Engineering Education, pp. 291-296.

WARD, J.H. (1963) Hierarchical grouping to optimize an objective function, fournal of American Statistical Association, 58, pp. 236-244. 